\title{
Human Evaluative Conditioning: Order of Stimulus Presentation
}

\author{
Marianne Hammerl and Hans-Joachm Grabitz \\ Heinrich-Heine-University Duesseldorf, Germany
}

\begin{abstract}
In an experiment designed to demonstrate evaluative conditioning, subjects were shown 48 pictures of sculptures that they rated on a scale with 21 categories $(-10$ to +10 ). Then, the two most liked pictures $(\mathrm{L})$ were paired with pictures from the categories $-1,0$, or $+1(N)$. In contrast to prior experiments, subjects were given either forward conditioning (N-L) or backward conditioning (L-N) trials but not both. Four other neutral stimuli were paired with each other (N-N) and acted as control stimulus pairs. After conditioning, the stimuli were rated a second time. There was a statistically significant difference in evaluative ratings showing a change of the evaluative tone of the previously neutral stimuli in a positive direction only after forward conditioning. This finding is inconsistent with results of prior experiments and challenges the assumption of Martin and Levey (1987) that evaluative conditioning is different from human classical conditioning.

Key Words-Classical conditioning, backward procedure, awareness, evaluative conditioning, humans.
\end{abstract}

THE TERM "EVAlUATIVE CONDITONING" refers to the phenomenon that mere contingent presentation of affectively neutral stimuli with liked or disliked stimuli is sufficient to change the evaluative tone of the neutral stimuli in a positive or negative direction. Empirical evidence extends from the well-known experiment of Staats and Staats (1957) to recent work on evaluative response change in attitude and behavior therapy research.

Although the procedural similarities to classical conditioning experiments are obvious, Martin and Levey (1987) argued that the process and the representational structure underlying evaluative conditioning are different from those involved in the tone-shock paradigm, measuring autonomic responses as indices of learning. The latter type of learning paradigm is assumed to involve expectancy or signal learning (Dawson \& Schell, 1987): The subject learns that the conditioned stimulus (CS) predicts the unconditioned stimulus (US). At the representational level, this view implies that the conditioning is mediated via learned CS-US associations, such that subsequent CS presentations will elicit some kind of internal representation of the US. For evaluative conditioning, Martin and Levey (1987) have offered a rather different theoretical position: The subject does not learn an "if-then" relationship between CS and US. Instead, the evaluative reaction evoked by the US is transferred to the CS, and thus, the CS itself becomes liked or disliked. This acquired evaluative meaning of the CS is supposed to be represented without reference to the US representation.

This theoretical position is inferred from the following findings. First, evaluative conditioning seems to occur in the absence of subjects' awareness of the CS-US relation

Address for correspondence: Marianne Hammerl, Dept. of Psychology, Heinrich-Heine-University Duesseldorf, Universitaetsstr. 1, D-4000 Duesseldorf 1, Germany (Email: HAMMERL@ZE8.RZ.UNIDUSSELDORF.DE).

Integrative Physiological and Behavioral Science, April-June, 1993, Vol. 28, No. 2, 191-194. 
(Baeyens, Eelen, \& Van den Bergh, 1990), whereas subjects' explicit knowledge of the CS-US contingency is supposed to be necessary for human classical conditioning (Dawson \& Schell, 1987, but see Furedy, 1991). Second, it has been demonstrated that the acquired evaluative value is resistant to subsequent extinction manipulations (Levey \& Martin, 1975). Third, unlike (human) classical conditioning, evaluative conditioning seems to be effectual in both forward (CS-US presentation) and backward (US-CS presentation) conditioning arrangements (Levey \& Martin, 1975; Shanks \& Dickinson, 1990).

The standard procedure in recent evaluative conditioning experiments is based on a within-subjects design. Subjectively neutral $(N)$ pictures are presented contingently with subjectively strongly liked (L) or disliked (D) pictures in either a forward (N-L, N-D) or backward (L-N, D-N) relationship. Two other neutral pictures are paired (N-N) and act as control stimulus pair. The finding is that subjects rate the pictures paired with liked pictures (N-L, L-N) more positively and the pictures paired with disliked pictures (N-D, D-N) more negatively than the neutral control pictures (N-N). Considering that the occurrence of evaluative conditioning in both forward and backward procedures implies important theoretical consequences, it is necessary to examine this procedural difference employing a between-subjects design. Therefore, we conducted the following experiment to determine whether forward and backward pairings are still effectual when they are realized independently of each other.

\section{Method}

\section{Subjects}

Twenty-two students of the Heinrich-Heine-University Duesseldorf (11 females, 11 males) majoring in subjects other than psychology were recruited as unpaid volunteers. Age ranged from 20 to 29 years with a mean of 24.57 years. The subjects were tested individually.

\section{Stimuli}

Stimulus materials were 48 color prints ( $9 \mathrm{~cm}$ wide by $13 \mathrm{~cm}$ long) of outdoor sculptures, located in public places and parks.

\section{Procedure}

Phase I. Subjects were told that the purpose of the study was to examine the influence of sculptures on the attraction of cities. They were instructed to rate the pictures by pointing to a scale $105 \mathrm{~cm}$ long, comprising of 21 categories $5 \mathrm{~cm}$ each. The categories were labeled $-10,-9, \ldots, 0, \ldots,+9,+10$. In addition, the scale was labeled "disliked" at the left and "liked" at the right. Each picture was displayed for $3 \mathrm{~s}$. The two pictures most liked were used as L stimuli, with the restriction that a minimum rating of 5 was obtained. The pictures from the categories $-1,0,+1$ were selected to act as $\mathbf{N}$ stimuli. While the subjects were preoccupied with a filler task (the subjects were led to believe that a measurement of their current mood via questionnaire was necessary), the following stimulus pairings were arranged: Two neutral stimuli were paired with liked stimuli in either a forward (N-L) or backward (L-N) relationship; four other neutral stimuli were paired with 
TABle 1. Descriptive Statistics for Evaluative Ratings of the Pictures Selected as Neutral (N) and Liked (L) Stimuli

\begin{tabular}{|c|c|c|c|c|}
\hline \multirow[b]{2}{*}{ Group } & \multirow[b]{2}{*}{$N / L$} & \multicolumn{2}{|c|}{ Stimuli } & \multirow[b]{2}{*}{$N$} \\
\hline & & $N / N$ & $L$ & \\
\hline \multicolumn{5}{|l|}{ Forward } \\
\hline$M$ & 0.00 & 0.07 & 8.93 & 0.07 \\
\hline$S D$ & 0.00 & 0.45 & 0.89 & 0.45 \\
\hline \multicolumn{5}{|l|}{ Backward } \\
\hline$M$ & 0.21 & 0.29 & 7.93 & -0.29 \\
\hline$S D$ & 0.39 & 0.49 & 1.67 & 0.57 \\
\hline
\end{tabular}

Note: $\mathrm{N} / \mathrm{L}$ and $\mathrm{N} / \mathrm{N}$ stimuli were neutral stimuli later paired with $\mathrm{L}$ and $\mathrm{N}$ stimuli, respectively.

each other (N-N) and thus acted as control stimulus pairs. For ethical reasons, no pairings with disliked stimuli were arranged.

Phase II. The subjects were randomly assigned to one of two groups, with sex balanced across groups. In each group, four different stimulus pairs were presented. In the first group, the subjects were shown two $\mathrm{N}-\mathrm{L}$ pairs and two $\mathrm{N}-\mathrm{N}$ pairs (forward group). In the second group, two L-N pairs and two N-N pairs were presented (backward group). Each stimulus pair was shown 10 times. Thus, a total of 40 stimulus pairs was presented. The order of presentation was completely randomized. Each stimulus was displayed for $3 \mathrm{~s}$. The interstimulus interval was $5 \mathrm{~s}$; the intertrial interval was $12 \mathrm{~s}$.

Phase III. Each stimulus that had been presented in Phase II was rated by the subjects using the scale previously described. Finally, they were interviewed to determine their awareness of the contingencies between the stimuli.

\section{Results}

In each group, the data of two subjects were excluded from further analyses because their highest initial rating of a picture did not meet the criterion of $\mathrm{L}$ stimuli. Initial mean evaluative responses to stimuli selected as $\mathbf{N}$ and $\mathrm{L}$ stimuli are shown in Table 1. Comparisons using Mann-Whitney $U$ tests yielded no statistically significant differences between the groups. A rejection level of $p>.05$ was adopted for this and all subsequent analyses.

In Figure 1, the difference scores of evaluative ratings (second measurement minus first measurement) are presented. The subjects of the forward group showed a significantly higher rating than the subjects of the backward group. In the forward group, statistical analysis using a Wilcoxon signed-rank test revealed a significant difference in the rating of stimuli paired with liked stimuli compared with the rating of stimuli paired with neutral stimuli (i.e., control stimulus pairs). In the backward group, there was no significant difference.

The postconditioning interview revealed that no subject was aware of the contingencies between the stimuli.

\section{Discussion}

The results of the present study show that the order of stimulus presentation has great impact on evaluative conditioning. Only after forward conditioning, a change of the evaluative tone of the previously neutral stimuli in a positive direction has occurred. This finding is inconsistent with results of prior experiments and challenges the assumption of 


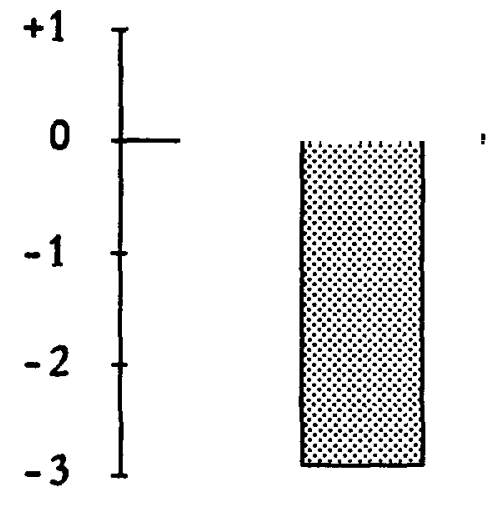

N/L
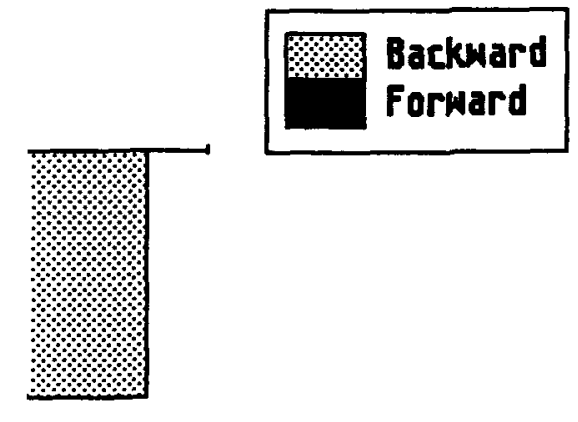

$\mathbf{N} / \mathbf{N}$

FIG. 1. Mean difference scores of evaluative ratings for previously neutral stimuli paired with liked (N/L) or neutral $(\mathrm{N} / \mathrm{N})$ stimuli.

Martin and Levey (1987) that evaluative conditioning is different from human classical conditioning. However, it must be added that in early classical conditioning literature it was not denied that a CS paired with a reinforcer will acquire some of the affective properties of that reinforcer (e.g., Miller, 1951).

In the present study, evaluative conditioning has occurred in the absence of awareness. However, we do not consider this finding as crucial. First, there are reasonable doubts about the validity of awareness measurement. Second, a consensus about the theoretical relevance of awareness is still lacking.

\section{References}

Baeyens, F., Eelen, P., \& Van den Bergh, O. (1990). Contingency awareness in evaluative conditioning: A case for unaware affective-evaluative learning. Cognition and Emotion, 4, 3-18.

Dawson, M.E., \& Schell, A.M. (1987). Human autonomic and skeletal classical conditioning: The role of conscious cognitive factors. In G. Davey (Ed.), Cognitive processes and Pavlovian conditioning in humans (pp. 27-55). Chichester, England: Wiley.

Furedy, J.J. (1991). Some recalcitrant views on the role of noncognitive S-R factors in human Pavlovian autonomic conditioning: Some facts still haunt us. Integrative Physiological and Behavioral Science, 26, 21-25.

Levey, A.B., \& Martin, I. (1975). Classical conditioning of human 'evaluative' responses. Behaviour Research and Therapy, 13, 221-226.

Martin, I., \& Levey, A.B. (1987). Learning what will happen next: Conditioning, evaluation, and cognitive processes. In G. Davey (Ed.), Cognitive processes and Pavlovian conditioning in humans (pp. 57-81). Chichester, England: Wiley.

Miller, N.E. (1951). Leamable drives and rewards. In S.S. Stevens (Ed.), Handbook of experimental psychology (pp. 435-472). New York: Wiley.

Shanks, D.R., \& Dickinson, A. (1990). Contingency awareness in evaluative conditioning: A comment on Baeyens, Eelen, and van den Bergh. Cognition and Emotion, 4, 19-30.

Staats, C.K., \& Staats, A.W. (1957). Meaning established by classical conditioning. Journal of Experimental Psychology, 54, 74-80. 